\title{
The Stress Problems and the Needs for Stress Counseling of High School Students in Vietnam
}

\author{
Son Huynh Van \\ Ho Chi Minh City \\ University of Education, \\ VIETNAM
}

\author{
Vu Giang Thien * \\ Ho Chi Minh City \\ University of Education, \\ VIETNAM
}

\author{
Thien Do Tat \\ Ho Chi Minh City \\ University of Education, \\ VIETNAM
}

\author{
Luong Tran \\ Can Tho University, \\ VIETNAM
}

\author{
Hoi Dinh Duc \\ Thai Nguyen \\ University, \\ VIETNAM
}

\begin{abstract}
The correlation between the stress problems and the needs for high school students' stress counseling in Vietnam is an unspecified issue that deserves attention. This study was conducted to test the hypothesis that there was no correlation between the stress problems and the needs for counseling of high school students in Vietnam. Survey of 1,200 high school students in Vietnam from grades 6 to 12 with questionnaires, the results show that the mean score of stress problems in high school students is 2.67 corresponding to moderate level. Different levels of learning and living conditions are encountered in different student's stress problems. The mean score for high school students' stress needs of counseling is 3.18 - corresponding to the optional level. Different levels of education have different needs for stress counseling. There is a strong correlation between high school students' problems and needs for stress counseling. The more problematic high school students experience in stress, the more they need to be counseled on this issue.
\end{abstract}

Keywords: Children, factors, incomplete family, psychological trauma, Vietnamese school counseling.

To cite this article: Son, H. V., Vu, G. T., Thien, D. T., Luong, T., \& Hoi, D. D. (2019). The stress problems and the needs for stress counseling of high school students in Vietnam. European Journal of Educational Research, 8(4), $1053-1061$. http://doi.org/10.12973/eu-jer.8.4.1053

\section{Introduction}

Psychological disturbances or social conflicts in Vietnamese high school students have recently been as a natural law and a more complicated situation. That the current condition of school violence, stress, depression, even suicidal intention is taking place publicly or silently within high school student communities is hard to be identified (Son, 2007). This reality is confirmed as one main factor resulting in stress in high school students' psychological life (Duc, 2014).

Many studies in the issue of stress during high school period, listing as: da Andaet al (2000) research on stress and stress factors; the correlation between stress and mental health among high school students conducted by Suldo, Shaunessy, and Hardesty(2008); the issue of study pressures and resolutions researched by Hussain, Kumar, and Husain (2008); the topic of academic stress, family pressure and mental health among high school students performed by Deb, Strodl, and Sun (2015); the correlation between study pressures and study motivations by Liu (2015); the situation of homosexual high school students' stress, anxiety and depression researched by Davies, and Kessel (2017), etc. Generally, the previous studies are performed in a deep manner from diverse perspectives, resulting in an overall picture regarding to the problems of high school students' stress.

Currently, in Vietnam, initially, stress researches are paid more attention and performed in a deeper level in medicine major and psychotherapy; nevertheless, not many studies related to students' stress, especially, the needs of stress counseling, have been conducted due to the fact that high school students, during their puberty period together with their distinctive psychological development, easily develop stress, anxiety, even depression mainly resulted from school, family and school impacts (Chi, 2011).

However, up to the present time, studies related to school psychological disturbances, especially academic stress or school counseling programs, remain as main challenges towards Vietnamese school system. The reality shows that very few school counseling programs for secondary school students and high school students is proposed to be researched

\footnotetext{
* Corresponding author:

Vu Giang Thien, Ho Chi Minh City University of Education, Vietnam. $\bowtie$ thienvust0708@gmail.com
} 
and performed with a methodical, professional and official methodology. This shortcoming requires the urgent demand in the performance of a large-scale plan in a professional and methodical way towards constructing school counseling models at high schools; in which, the current situation of stress as well as the need of stress counseling proves the necessity of proposing one standard school counseling model with the aim of supporting high school students' mental health in future.

\section{Methodology}

\section{Research hypothesis}

$\mathrm{H}_{01}$ : High school students in Vietnam do not suffer from stress related issues $\left(\mathrm{H}_{01 \mathrm{a}}\right)$. High school students' stress levels are within acceptable levels and easily adjusted. Therefore, Vietnamese high school students do not need to counsel about stress $\left(\mathrm{H}_{01 \mathrm{~b}}\right)$.

$\mathrm{H}_{02}$ : There is no correlation between gender indicator in students' stress encountered problems ( $\left.\mathrm{H}_{02 \mathrm{a}}\right)$ as well as the need for stress counseling $\left(\mathrm{H}_{02 \mathrm{~b}}\right)$.

$\mathrm{H}_{03}$ : There is no correlation between the education level indicator in students' stress encountered problems ( $\left.\mathrm{H}_{03 \mathrm{a}}\right)$ as well as the need for stress counseling $\left(\mathrm{H}_{03 \mathrm{~b}}\right)$.

$\mathrm{H}_{04}$ : There is no correlation between living condition (family background) indicator in students' stress encountered problems $\left(\mathrm{H}_{04 \mathrm{a}}\right)$ as well as the need for stress counseling $\left(\mathrm{H}_{04 \mathrm{~b}}\right)$.

$\mathrm{H}_{05}$ : There is no correlation between the stress problems and the need for stress counseling of high school students.

\section{Study design}

Questionnaires and situations are designed to survey 1,200 students from grade 6 to grade 12 in Vietnam. The survey lasts from January to April 2018. Research tools are designed to meet the demands of reality research criteria (fewer than 30 items).

We inherited and used a questionnaire which was based on the DASS21 scale and connected with the characteristics of stress problems in Vietnamese students (Le, Tran, Holton, Nguyen, Wolfe \& Fisher, 2017). This method was conducted using an open questionnaire for the initial survey to study the opinions of 75 students from Ho Chi Minh City, Vietnam. Then, a questionnaire with 12 questions was developed to survey 1200 high school students on the student's problems encountered related to stress and the need of stress counseling. Based on the reliability of the questionnaire with 0.86 at the alpha 0.01 level, an official questionnaire was completed (see Table 1). We also interviewed 3 psychotherapists about the reliability of the questionnaire as well as added suggestions to enhance the reliability of the items. The official questionnaire consisted of 10 questions and eliminated 2 questions that did not meet all the basic requirements after the test. The item is comprised of the following questions of the situation and high school students' needs of stress counseling. 5 questions evaluate the problems encountered that are related to stress as well as 5 questions evaluated high school students' need of stress counseling. The items are designed with 5-point Likert scale (Croasmun \& Ostrom, 2011).

\section{Data analysis}

Using Likert 5 point for range value and point division:

Range $=($ Maximum - Minimum $) / n=0.8$

Therefore, the meanings are as below:

- 1 to $1.80=$ Totally none/ Totally unnecessary

- 1.81 to 2.61= Under average/Unnecessary

- 2.62 to 3.42= Moderate/Optional

- 3.43 to 4.23 = Rather difficult/ Necessary

- 4.24 to 5 = Very difficult/ Totally necessary

This article uses SPSS for Windows tool to process research data with the help of calculations as analysis of variance Anova test, Pearson Correlation - results are used for supportive evaluations (test the $\mathrm{H}_{02}, \mathrm{H}_{03}$ and $\mathrm{H}_{04}$ ) whereas $\mathrm{Mean}_{\text {, }}$ Std. Deviation, Percent, Frequencies calculations - results are used for qualitative evaluations (test the $\mathrm{H}_{01}$ ).

\section{Survey participants}

The participants are selected randomly from 7 high schools (SS = Secondary school; HS = Highschool) in 5 central cities in Vietnam with 1,200 students as in table 1: 
Table 1. General information of participants

\begin{tabular}{llcc}
\hline Content & & $\mathbf{n}$ & $\mathbf{\%}$ \\
\hline \multirow{2}{*}{ Gender } & Male & 449 & 37.4 \\
School level & Female & 751 & 62.6 \\
& Secondary school (from grade 6 to 9) & 726 & 60.5 \\
& Highschool (from grade 10 to 12) & 474 & 39.5 \\
& Grade 6 & 68 & 5.7 \\
Grade & Grade 7 & 9 & 0.8 \\
& Grade 8 & 325 & 27.1 \\
& Grade 9 & 324 & 27.0 \\
& Grade 10 & 69 & 5.8 \\
Living condition & Grade 11 & 246 & 20.5 \\
(Family status) & Grade 12 & 159 & 13.3 \\
& With both parents & 1026 & 85.5 \\
\hline
\end{tabular}

n: Number of participants; \%: Percentage

\section{Results}

The concerned stress problems of high school students in Vietnam

The current situation of the problems encountered related to stress of high school students is described in Table 2:

Table 2. High school students' stress problems

\begin{tabular}{|c|c|c|c|c|c|c|c|c|c|}
\hline \multirow{2}{*}{ Expressions } & & \multicolumn{5}{|c|}{ Levels } & \multirow{2}{*}{$\mathbf{M}$} & \multirow{2}{*}{ SD } & \multirow{2}{*}{ Order } \\
\hline & & 1 & 2 & 3 & 4 & 5 & & & \\
\hline \multirow{2}{*}{$\begin{array}{l}\text { Understanding negative expressions and personal } \\
\text { moods }\end{array}$} & $\mathrm{n}$ & 251 & 241 & 454 & 161 & 93 & \multirow{2}{*}{2.67} & \multirow{2}{*}{1.172} & \multirow{2}{*}{2} \\
\hline & $\%$ & 20.9 & 20.1 & 37.8 & 13.4 & 7.8 & & & \\
\hline \multirow{2}{*}{$\begin{array}{l}\text { Identifying pressures from particular situations or } \\
\text { individuals }\end{array}$} & $\mathrm{n}$ & 262 & 251 & 427 & 167 & 93 & \multirow{2}{*}{2.65} & \multirow{2}{*}{1.187} & \multirow{2}{*}{3} \\
\hline & $\%$ & 21.8 & 20.9 & 35.6 & 13.9 & 7.8 & & & \\
\hline \multirow{2}{*}{ Identifying personal stressful situation } & $\mathrm{n}$ & 269 & 273 & 412 & 162 & 84 & \multirow{2}{*}{2.60} & \multirow{2}{*}{1.175} & \multirow{2}{*}{5} \\
\hline & $\%$ & 22.4 & 22.8 & 34.3 & 13.5 & 7.0 & & & \\
\hline \multirow{2}{*}{ Identifying the true causes producing stress } & $\mathrm{n}$ & 272 & 251 & 428 & 159 & 90 & \multirow{2}{*}{2.62} & \multirow{2}{*}{1.185} & \multirow{2}{*}{4} \\
\hline & $\%$ & 22.7 & 20.9 & 35.7 & 13.3 & 7.5 & & & \\
\hline \multirow{2}{*}{ Reacting to stressful situations in a positive manner } & $\mathrm{n}$ & 215 & 285 & 384 & 217 & 99 & \multirow{2}{*}{2.75} & \multirow{2}{*}{1.185} & \multirow{2}{*}{1} \\
\hline & $\%$ & 17.9 & 23.8 & 32.0 & 18.1 & 8.3 & & & \\
\hline$\overline{\mathbf{X}}$ & & & & & & & 2.66 & 1.016 & \\
\hline
\end{tabular}

1: Totally none; 2: Under average; 3: Average; 4: Rather difficult; 5: Very difficult;

n: Number of participants; \%: Percentage; M: Mean; SD: Standard deviation

$\overline{\mathrm{X}}=2.66$, equivalent to moderate point. The highest indicators, in descending level, are as below: "Reacting to stressful situations in a positive manner" indicator has the highest mean (2.75), the second as "Understanding the positive expression and personal mood" with the mean as 2.67, the third highest mean as "Identifying the pressures from particular situations or individuals" (2.65), the fourth as "Identifying the true causes producing stress" with 2.62 as well as "Identifying personal stressful situations" with the mean as 2.60. Based on this result, we realized that there was a spread between the level of the problems encountered to stress, there were students with no problems at all, but there were also cases where the situation was very difficult. Therefore, the hypothesis $\mathrm{H}_{01 \mathrm{a}}$ is rejected.

Our group verifies the differences among students' gender, school levels and living conditions in correlation with stress problems (see Table 3 and Table 4):

Table 3. Independent Samples Test on the problems encountered related to stress (gender and school level)

\begin{tabular}{|c|c|c|c|c|c|c|c|c|c|}
\hline Sources & & $\mathbf{n}$ & $\mathbf{M}$ & SD & SE & $\mathbf{F}$ & $\mathbf{t}$ & df & Sig. (2-tailed) \\
\hline \multirow{2}{*}{ Gender } & Male & 449 & 2.59 & 1.115 & .05262 & \multirow{2}{*}{21.474} & \multirow{2}{*}{-1.764} & \multirow{2}{*}{1198} & \multirow{2}{*}{.078} \\
\hline & Female & 751 & 2.70 & .951 & .03469 & & & & \\
\hline \multirow[t]{2}{*}{ School level } & $\begin{array}{l}\text { Secondary } \\
\text { school }\end{array}$ & 726 & 2.61 & 1.057 & .03924 & \multirow[t]{2}{*}{9.085} & \multirow{2}{*}{-2.115} & \multirow[t]{2}{*}{1198} & \multirow[t]{2}{*}{.035} \\
\hline & High school & 474 & 2.73 & .946 & .04344 & & & & \\
\hline
\end{tabular}

n: number of participants; M: Mean; SD: Standard deviation; SE: Standard Error Mean 
Table 4. Anova test on the problems encountered related to stress (living condition)

\begin{tabular}{lccccc}
\hline & SS & df & MS & F & Sig. \\
\hline Between Groups & 17.198 & 3 & 5.733 & 5.616 & .001 \\
Within Groups & 1220.874 & 1196 & 1.021 & & \\
Total & 1238.072 & 1199 & & & \\
\hline SS: Sum of Squares; MS: Mean Square & & &
\end{tabular}

SS: Sum of Squares; MS: Mean Square

Regarding to gender indicator, there was no significant difference related to stress problems between male $(\mathrm{M}=2.59$, $\mathrm{SD}=1.115)$ and female $(\mathrm{M}=2.70, \mathrm{SD}=.951)$ students; $\mathrm{t}(1198)=-1.764, \mathrm{p}=.078$, affirmed Hypothesis $\mathrm{H}_{02 \mathrm{a}}$ being accepted. In other words, the stressful level between male and female is equivalent.

Regarding to school level indicator, there was a significant difference of stress problems among students from secondary schools $(M=2.61, S D=1.057)$ and those from high schools $(M=2.73, S D=.946) ; t(1198)=-2.115, p=.035$, affirmed Hypothesis $\mathrm{H}_{03}$ being rejected. In other words, the higher grades students are in, the more stress problems they face.

Regarding to living condition (family status) indicator, there was a significant effect in the stress problems among students with different living conditions at the $p<.05$ level for the four conditions $[F(3,1196)=5.616, p=.001]$. Therefore, Hypothesis $\mathrm{H}_{04 a}$ is rejected.

\section{The need for stress counseling of high school students in Vietnam}

Along with finding out the situation of stress problems, we also surveyed the need for stress counseling of high school students (see Table 5).

Table 5. Students' need of stress counseling

\begin{tabular}{|c|c|c|c|c|c|c|c|c|c|}
\hline \multirow{2}{*}{ Expression } & & \multicolumn{5}{|c|}{ Level } & \multirow{2}{*}{ M } & \multirow{2}{*}{ SD } & \multirow{2}{*}{ Order } \\
\hline & & 1 & 2 & 3 & 4 & 5 & & & \\
\hline \multirow{2}{*}{$\begin{array}{l}\text { Understanding negative expressions and } \\
\text { personal moods }\end{array}$} & $\mathrm{n}$ & 198 & 143 & 305 & 306 & 248 & \multirow{2}{*}{3.22} & \multirow{2}{*}{1.347} & \multirow{2}{*}{1} \\
\hline & $\%$ & 16.5 & 11.9 & 25.4 & 25.5 & 20.7 & & & \\
\hline \multirow{2}{*}{$\begin{array}{l}\text { Identifying pressures from particular } \\
\text { situations or individuals }\end{array}$} & $\mathrm{n}$ & 223 & 181 & 227 & 372 & 197 & \multirow{2}{*}{3.12} & \multirow{2}{*}{1.360} & \multirow{2}{*}{4} \\
\hline & $\%$ & 18.6 & 15.1 & 18.9 & 31.0 & 16.4 & & & \\
\hline \multirow{2}{*}{ Identifying personal stressful situations } & $\mathrm{n}$ & 176 & 206 & 224 & 381 & 213 & \multirow{2}{*}{3.21} & \multirow{2}{*}{1.321} & \multirow{2}{*}{2} \\
\hline & $\%$ & 14.7 & 17.2 & 18.7 & 31.8 & 17.8 & & & \\
\hline \multirow{2}{*}{ Identifying true reasons causing tensions } & $\mathrm{n}$ & 202 & 181 & 265 & 341 & 211 & \multirow{2}{*}{3.15} & \multirow{2}{*}{1.338} & \multirow{2}{*}{3} \\
\hline & $\%$ & 16.8 & 15.1 & 22,1 & 28.4 & 17,6 & & & \\
\hline \multirow{2}{*}{$\begin{array}{l}\text { Reacting against stressful situations in a } \\
\text { positive manner }\end{array}$} & $\mathrm{n}$ & 236 & 136 & 224 & 349 & 255 & \multirow{2}{*}{3.21} & \multirow{2}{*}{1.414} & \multirow{2}{*}{2} \\
\hline & $\%$ & 19.7 & 11.3 & 18.7 & 29.1 & 21.3 & & & \\
\hline & & & & & & & 3.18 & 1.223 & \\
\hline
\end{tabular}

1=Absolutely unnecessary; 2=Unnecessary; 3=Optional; 4= Necessary; 5=Very necessary; n: Number of participants; \%: Percentage; M: Mean; SD: Standard deviation

$\overline{\mathrm{X}}=3.18$ evaluated as optional. The highest indicators, from the highest to the lowest, are as below: Students have the highest need in "Understanding the negative expressions and personal moods" with mean as 3.22, the second is "Identifying personal stressful situation" with 3.21, the third as "Identifying the true reasons causing tensions" with 3.15 , the final as "Identifying the tensions from particular situations or individuals" with 2.60. This order shows that most high school students need to understand more clearly and better their negative personal expressions and emotions as well as the ways to identify the main reasons causing these tensions. Through this result, we can see that Vietnamese high school students need to be counseled on stress problems. Therefore, the hypothesis $\mathrm{H}_{01 \mathrm{~b}}$ that we propose is not accepted.

Our group verifies the differences in students' stress counseling needs based on gender, school level, living conditions with the following results (see Table 6 and Table 7):

Table 6. Independent Samples Test on the need of stress counseling (gender and school level)

\begin{tabular}{|c|c|c|c|c|c|c|c|c|c|}
\hline \multicolumn{2}{|c|}{ Sources } & $\mathrm{n}$ & $\mathrm{M}$ & SD & SE & $\mathrm{F}$ & $\mathrm{t}$ & $\mathrm{df}$ & Sig. (2-tailed) \\
\hline \multirow{2}{*}{ Gender } & Male & 449 & 2.95 & 1.253 & .05914 & \multirow{2}{*}{1.282} & \multirow{2}{*}{-5.144} & \multirow{2}{*}{1198} & \multirow{2}{*}{.000} \\
\hline & Female & 751 & 3.32 & 1.185 & .04324 & & & & \\
\hline \multirow{2}{*}{ School level } & $\begin{array}{l}\text { Secondary } \\
\text { school }\end{array}$ & 726 & 3.02 & 1.260 & .04675 & \multirow{2}{*}{12.511} & \multirow{2}{*}{-5.654} & \multirow{2}{*}{1198} & \multirow{2}{*}{.000} \\
\hline & High school & 474 & 3.42 & 1.125 & .05166 & & & & \\
\hline
\end{tabular}

n: number of participants; M: Mean; SD: Standard deviation; SE: Standard Error Mean 
Table 7. Anova test on the need of stress counseling (living condition)

\begin{tabular}{lccccc}
\hline & SS & df & MS & F & Sig. \\
\hline Between Groups & 55.457 & 3 & 18.486 & 12.707 & .000 \\
Within Groups & 1739.903 & 1196 & 1.455 & & \\
Total & 1795.360 & 1199 & & & \\
\hline
\end{tabular}

SS: Sum of Squares; MS: Mean Square

Regarding to gender indicator, there was a significant difference related to the need of stress counseling between male $(\mathrm{M}=2.95, \mathrm{SD}=1.253)$ and female $(\mathrm{M}=3.32, \mathrm{SD}=1.185)$ students; $\mathrm{t}(1198)=-5.144, \mathrm{p}=.000$, affirmed Hypothesis $\mathrm{H}_{02 \mathrm{~b}}$ being rejected.

Regarding to school level indicator, there was a significant difference of the need of stress counseling among students from secondary schools $(M=3.02$, $S D=1.260)$ and those from high schools $(M=3.42, S D=1.125) ; t(1198)=-5.654, p$ $=.000$, affirmed Hypothesis $\mathrm{H}_{03 \mathrm{~b}}$ being rejected.

Regarding to living condition (family status) indicator, there was a significant effect in the need of stress counseling among students with different living conditions at the $\mathrm{p}<.05$ level for the four conditions $[F(3,1196)=12.707, p=$ .000]. Therefore, Hypothesis $\mathrm{H}_{04 \mathrm{~b}}$ is rejected.

Positive correlation between the stress problems and need for stress counseling of Vietnamese high school students

Table 8 below represented the result when using Pearson Correlation test to find out the correlation between the stress problems and need for stress counseling:

Table 8. Correlative coefficient between the stress problems and need for stress counseling of high school students

\begin{tabular}{lcc}
\hline & Stress problems & Need for stress counseling \\
\hline Stress problems & 1 & .58 \\
Need for stress counseling & .58 & 1 \\
\hline
\end{tabular}

**. Correlation is significant at the 0.01 level (2-tailed).

$\mathrm{p}=.000$ affirms one direct correlation between stress problems and students' need of stress counseling (Hypothesis $\mathrm{H}_{05}$ rejected).

\section{Discussion}

Regarding to the proportion in table 2, a lot of students face stress difficulties (the total sum of points $3,4,5$ is beyond $50 \%$ ). This figure raises our concern whether school counseling program is absolutely effective or not. What methods have been applied in the current school counseling program to assist students potential to stress? Is there a correlation between stress factor and other indicators because stress, with its genuine character, is long-term extended psychological tension, causing negative feelings to the subjects and these subjects themselves do not know how to handle these negative emotions (Simmons\& Daw, 2018).

The research on Indian high school students' mental health by Deb, Strodl, and Sun (2015) includes 190 Indian students in grades 11 and 12 (average age: 16.72) from 3 public schools and 3 private ones. Nearly two-thirds of the participants (63.5\%) have stress due to study pressure - implying no difference in gender, age, grades and other personal elements. Approximately two-thirds of the students (66\%) suffer pressures related to academic results from parents' expectations. Parental pressures change differently based on parents' academic background, mothers' occupations, the number of private tutors and study outcomes. About one-third (32.6\%) expresses mental health symptoms and $81.6 \%$ are concerned about testing and meeting school counseling mentors for their mental health condition check-up. Many students have stress because they cannot handle stressful situations (especially pressures from parents) in a positive manner; therefore, they face difficulties in understanding their own expressions and negative emotions, leading to being stressful and their mental and physical life is impacted. Consequently, the problems related to students' stress mainly originates from the fact that they do not know how to face the stressful situations in a positive way. Those social workers in school counseling program should be more aware of this issue in proposing the assistance and intervention strategies towards students' psychological problems.

Our results prove that high school students are well aware of their personal mental health conditions; however, the limits in living experiences as well as the lack of life-skills, they need to discover more and receive explanations from school counselors. The final outcomes they aim at is emotion understanding, difficulty identification and resolutions against these stressful situations in a positive manner. Although the means are at optional level, the proportion indicates a high number of students requiring the need to be counseled on stress, in which the total mean of levels 4 and 5 for each item is almost similar to or beyond 50\%. Allen, and Hiebert (1991) conducted a research on teenagers' assistance need in facing academic stress and life stress and presented the similar results. 285 students from grade 10 , 11 and 12 were surveyed on different needs in facing stress, their opinions of how to deal with these needs and the tension levels produced from these situations. The result showed that teenagers with a bigger support or assistance 
from family, school and society showed that their stress levels were lower with less frequent stress symptoms. Moreover, the stress level in teenagers was higher as well as teenagers' support sources fewer than those of the general population. The difference in stress level depends on the external support, including school counseling program. If teenagers were counseled on stress problems better and more effectively, their stress level would be decreased and they could be able to fight against those negative emotions. Generally, Vietnamese students' need of stress counseling and that of international students are similar in some definite aspect; resulting in the urgent necessity of building a mental health support model in schools to assist students - in other words, that is the model of school counseling program.

Within gender indicator, one study about stress problems in China by Yuan, W., Zhang, and Fu (2017) on 563 high school students (280 boys, 275 girls, 8 unidentified-gender) from grade 7 to 12 showed that age and gender have no direct relation and they are not related to stress-causing factors; rather, this impact comes from awareness background and critical thinking feature as well as personal reactions against stress-causing factors. Reddy, Kannekanti, and Hamza (2015) share the similar viewpoint in their research related to stress problems as well as public and private high school students' self-esteem in India. The result proves that there is no difference in gender regarding to students' stress problems. Consequently, we affirm that gender indicator can be ignored in studying high school students' stress problems. Besides, female students have higher need of stress counseling than male students make sense when analyzed from gender viewpoint (Duc, 2014). Girls have the tendency to look for external assistance when they do not feel comfortable. They come to school counseling office for more support compared to boys (Thien, Hoang, and Vu, 2018). Girls' thoughts and behaviors are more mature than those of boys at the same age (Tuet al., 2016). Therefore, the difference in the need of stress counseling from gender perspective is logical. This information is crucial to be paid more attention so that school counseling program can meet students' demands so as to play an important role in directing students' character development in a balancing and healthy manner.

Within school level indicator, the result is completely correlated and matching compared to the current condensed education program in Vietnam from secondary level to high school level. The secondary level is comprised of four grades: from grade 6 to grade 9 , starting from 11 to 14 years old. This secondary level is a compulsory educational level for Vietnamese citizens to follow one particular career because those students graduating from secondary level can begin vocational program or professional middle-college level without graduating from high school. Students must complete the following subjects: Mathematics, Physics, Chemistry (grade 8 and 9), Biology, Technology, Literature, History, Geography, Civic Education, Foreign languages, Physical Education, Music and Art (at the first semester of grade 9), Informatics (optional). Furthermore, secondary students must study: extra-class education, occupational orientation and so on. Before continuing high school level, secondary level students have to pass a graduating examination. High school level is comprised of three grades: from grade 10 to 12, starting from 15 to 17 years old. In order to pass the high school level, students must take part in high school graduation examination in Vietnam managed by Vietnamese Ministry of Education and Training. Those wishing to study at high school level must take an entrance examination after finishing the secondary level and they are selected based on their overall score during 4 years in secondary level. These examinations are organized annually and hosted by Department of Education and Training at Provincial level. In this education level, students must study similar subjects to secondary level besides Army Education but they do not have to study Music and Art subjects. However, high school students can take part in other programs as career orientation or vocational training as usual (MOET, 2013). The study program is getting more and more condense besides the continuous testing pressures is one crucial element causing extended and long-term stress and worry towards most high school students (Son, 2007). This is also one reason for Vietnamese government to alter the current educational program and launch the new one in 2020 after the official introduction in 2018. At secondary level, many students (at grade 6 and 7 or at pre-puberty period) still remaining their child-like characters and thinking, come immediately to parents or teachers to talk about their problems without any doubt or disbelief. However, at grade 8 and 9 or during puberty period, these students begin to be suspicious or doubtful of the relations around them, they have the tendency to narrow their personal space and share less to parents or teachers so their need of stress counseling is less obvious and outstanding. Nevertheless, after the transition time to high school level, study and testing pressures as well as changes in new study environment and friendship transform some students to be unbalanced and confused. They gradually cannot control themselves any longer. They need the external assistance, resulting in the higher need of stress counseling (Duc, 2014). Therefore, different school levels result in different needs of stress counseling. As a result, the school counseling activity and the identification of school counseling content must be based on many indicators, in which, age distinctiveness plays a crucial role. This issue can differentiate the counseling models applied for secondary schools and high schools in general and educational duty in particular.

Students with different living conditions face different levels of stress. We discover one contradiction in the mean score among these results. Those students living with parents or relatives face fewer stress problems than those living with mother or with both parents. According to Downey(1994), there is one difference in the study pressure and academic result of those children in single-father family compared to that of those in single-mother family as well as those living with both parents, based on data collected from 409 students from single-father families, 3,483 children with singlemother families and 14,269 students from father-and-mother families. Children from single-father and single-mother families face similar stress problems in study pressures and academic results; however, these two groups are more 
outstanding compared to those from father-and-mother families. Nevertheless, there exist differences among the intervention processes to explain study pressures and study results for those from single-father and single-mother families. Lack of financial condition in single-mother families explains the reason why children from these family types face more mental health problems (including stress) than those living in single-father families. Another research related to children' psychological trauma in a complete family compared to incomplete family by My(2019) introduced a new perspective for this topic: children living in incomplete families (single-father, single-mother, living with relatives) facing more mental problems than those living in complete families with both parents. Pryor, and Rodgers (2001) share the same viewpoint that children living in divorced-parents families face more disorders (stress, anxiety, depression) than those living in happy families with both parents. Therefore, compared to other international studies, our group figure out the influences of family conditions on students' stress problems; nevertheless, no unified common feature has been discovered. This is one humanely field paid more attention by researches and this hypothesis verification should be performed for further affirmation.

Different living conditions result in different needs of stress counseling. Especially, students living in single-father and single-mother families have the highest average point. This clarifies some concerning questions in table 3 related to the problems that students living in single-father and single-mother families may face. In combination of explanations from table 3 and data from table 5 besides an overview from previous researches on the influences of single-father and single-mother families upon children' psychological development, listing as Williams, and Radin (1999) researching on the differences in children raising between single-fathers and single-mothers; Dufur, Howell, Downey, Ainsworth, and Lapray (2010) surveying on children behaviors in single-father and single-mother families; Lee (2018) interested in family structure on children' psychological development and so on. These researches strengthen the viewpoint that children living in single-father or single-mother families face some certain psychological trauma that have been affecting their mental life; for example: anxiety, tension, depression, or rebellion, self-destruction, social isolation. As school counselors and researchers, our group is completely concerned with this reality and aim at proposing more profound research directions for further suggestions assisting unlucky children facing these living conditions above.

Our study denies the hypothesis that whether there exists no correlation between stress problems and Vietnamese students' need of stress counseling. The more stress students face, the higher the need of stress counseling becomes; especially problems as confidence and comfort during stress in communication to others or controlling linguistic use and non-linguistic behaviors during stress. This crucial information needs to be solved as soon as possible so as to form the stress-related-problem solving skill for students to balance and organize their life well. Simmons, and Daw (2018), while researching stress and worry treatment therapy, present similar viewpoints. When human beings face extended tension condition, they gradually lose their consciousness, they cannot control themselves and it is easy for them to bring in stimulated and rebellious activities. At that time, they are still aware of their negative behaviors and thinking but nothing can they do to control themselves. This worsens their situations. After calming down, they do not know what to do, all they need is assistance. The need of counseling and treated with therapy initiates and they are in need of help and support from counseling experts in providing ways for them to get away from this chaos. From this, the need of counseling is shaped and develops in a blooming direction according to stress problems. Based on the above proof, it can be seen that Vietnamese students face similar situations in facing stress; therefore, our data collection and analyzed outcomes can be concluded objectively as meaningful and practical.

\section{Conclusion}

Vietnamese high school students are facing stress problems and do have the need of stress counseling. They represent their desire in finding the reasons causing stress as well as more positive solutions against stress and how to identify these problems through research data analysis. There is a correlation between stress problems and students' need of stress counseling. The more stress problems students face, the higher the need of stress counseling becomes.

On the other hand, the reality at Vietnamese schools cannot meet the requirements of school counseling duty in order to assist students related to stress problems (Son, 2019). The quantity and quality criteria of school counseling resources and investment scale from zone governmental managers and school principle boards have not been completely decisive and outstanding enough for a boosting effect (Hong, 2017). Therefore, in the completely new Vietnamese educational change, especially, new educational schedule to be launched in 2020, school counseling program must be paid appropriate attention with suitable and correct working directions; in which, stress counseling activity must be enhanced and matching to reality so that students are more confident to balance their study and living life.

\section{References}

Allen, S., \& Hiebert, B. (1991). Stress and coping in adolescents. Canadian Journal of Counselling and Psychotherapy/Revue canadienne de counseling et de psychotherapie, 25(1), 777 - 780.

Chi, T. T. (2011). Kho khan tam ly trong cong tac tham van học duong tại TP.HCM [The students' psychological difficulty in Ho Chi Minh City] (Unpublished master's thesis). Ho Chi Minh City University of Education, Ho Chi Minh City, Vietnam. 
Croasmun, J. T., \& Ostrom, L. (2011). Using Likert-Type Scales in the Social Sciences. Journal of Adult Education, 40(1), 19-22.

Davies, R. D., \& Kessel, B. (2017). Gender Minority Stress, Depression, and Anxiety in a Transgender High School Student. American Journal of Psychiatry, 174(12), 1151-1152

de Anda, D., Baroni, S., Boskin, L., Buchwald, L., Morgan, J., Ow, J., ... \& Weiss, R. (2000). Stress, stressors and coping among high school students. Children and youth services review, 22(6), 441-463.

Deb, S., Strodl, E., \& Sun, J. (2015). Academic stress, parental pressure, anxiety and mental health among Indian high school students. International Journal of Psychology and Behavioral Sciences, 5(1), 26-34.

Downey, D. B. (1994). The school performance of children from single-mother and single-father families: Economic or interpersonal deprivation?. Journal of family issues, 15(1), 129-147.

Duc, T. T. M. (2014). Tham van học duong [Practice: School counseling]. Ha Noi, Vietnam: Safe, friendly and equal school projects.

Dufur, M. J., Howell, N. C., Downey, D. B., Ainsworth, J. W., \& Lapray, A. J. (2010). Sex differences in parenting behaviors in single-mother and single-father households. Journal of Marriage and Family, 72(5), 1092-1106.

Hong, N. T. M. (2017). Phat trien doi ngũ chuyen vien tham van học duong o khu vuc phía Nam [Solutions to develop the school counselor staffs in Vietnamese Southern area] (Ministry-level scientific and technological research). Ho Chi Minh City University of Education, Ho Chi Minh City, Vietnam.

Hussain, A., Kumar, A., \& Husain, A. (2008). Academic stress and adjustment among high school students. Journal of the Indian academy of Applied Psychology, 34(9), 70-73.

Le, M. T. H., Tran, T. D., Holton, S., Nguyen, H. T., Wolfe, R., \& Fisher, J. (2017). Reliability, convergent validity and factor structure of the DASS-21 in a sample of Vietnamese adolescents. PloS one, 12(7), e0180557.

Lee, S. A. (2018). Family structure effects on student outcomes. In Parents, their children, and schools (pp. 43-76). New York, NY: Routledge.

Liu, Y. (2015). The longitudinal relationship between Chinese high school students' academic stress and academic motivation. Learning and Individual Differences, 38, 123-126.

My, N. T. D. (2019). Giải phap giảm thieu ton thuong tam ly cua trẻ em trong gia dinh khong toan vẹn [Solutions to reduce the psychological trauma of children living in the incomplete families] (Ministry-level scientific and technological research). Ho Chi Minh City University of Education, Ho Chi Minh City, Vietnam.

Pryor, J., \& Rodgers, B. (2001). Children in changing families: Life after parental separation. Malden, MA: Blackwell Publishing.

Reddy, S., Kannekanti, P., \& Hamza, A. (2015). A comparative study on self-esteem and stress among private and government high school students. IJRSI, 2(3), 18-22.

Simmons, M., \& Daw, P. (2018). Stress, Anxiety, Depression: A guide to humanistic counselling and psychotherapy. London, England: Routledge.

Son, H. V. (2019, May). Thuc trang cong tac tu van hoc duong tại thanh pho Can Tho [The reality of school counseling in Can Tho City]. Paper presented at the Conference on the Reality of school counseling model in Can Tho city high schools, Ho Chi Minh city University of Education, Ho Chi Minh City, Vietnam.

Son, L. (2007). Tu van học duong va moi truong giao dục [School counseling and Educational environment]. Ho Chi Minh City, Vietnam: Institute of Educational Research and Business Administration.

Suldo, S. M., Shaunessy, E., \& Hardesty, R. (2008). Relationships among stress, coping, and mental health in highachieving high school students. Psychology in the Schools, 45(4), 273-290.

Thien, D. T., Hoang, N. L. B., \& Vu, G. T. (2018). Nghien cuu v hanh vi tu co lap - Huong nghien cuu can quan tam o học duong [Self-isolation behavior study - A concern in Vietnamese school counseling]. In Proceeding of the 6th International Scientific Conference on School Psychology - The role of School Psychology in ensuring mental health for students and families (pp.867-876). Ha Noi, Vietnam: Hanoi University of Education Publisher.

Tu, N. T. \& et al. (2016). Giao trinh Tam ly hoc lua tuoi v Tam ly hoc su pham [Curriculum of Age psychology and Pedagogical psychology]. Ho Chi Minh City, Vietnam: Ho Chi Minh City University of Education Publisher.

Vietnamese Ministry of Education and Training (MOET). (2013). Quyet dịh 1215/QD/BGDDT ngay 4 thang 4 nam 2013 ban hanh Chuong trinh hanh dong cua nganh giao duc thuc hien chien luoc phat trien giao duc Viet Nam 2011-2020 [Decision 1215 / QD /BGDDT dated April 4th, 2013 promulgating the Action Program of the education sector to 
implement Vietnam's education development strategy 2011-2020]. Hanoi, Vietnam: Vietnamese Government Publishing Service.

Williams, E., \& Radin, N. (1999). Effects of father participation in child rearing: Twenty-year follow-up. American Journal of Orthopsychiatry, 69(3), 328-336.

Yuan, W., Zhang, L. F., \& Fu, M. (2017). Thinking styles and academic stress coping among Chinese secondary school students. Educational psychology, 37(8), 1015-1025. 